\title{
USE OF PESTICIDES AND ITS RESIDUE ON VEGETABLE CROPS IN NEPAL
}

Dilli Ram Sharma ${ }^{1}$

\begin{abstract}
Farmer field survey and lab residue analysis studies were carried out to examine the use of pesticide in vegetable fields and its potential effects on human health and environment. Field information were collected using semi-structured questionnaires face to face interview with 200 farmers from three districts (Bara, Dhading and Kavre) of central region of Nepal. The recent study showed that the use of chemical pesticides in Nepal is $0.396 \mathrm{Kg}$ a.i./ ha. The farmers' field survey showed that 72 percent of the farmers paid attention on acquiring information about the effectiveness of pesticide to control the target pests. While 65 percent of the farmers noticed the expiry date of pesticides, and only a few farmers considered the adverse effects of pesticide on human health and environment. The result showed that majority of them (51.5\%) kept the remaining pesticides in their house freely, whereas 23.5 percent farmers destroyed the remaining pesticides; either buried or burnt. It was also found that 22.5 percent of farmers did not care and threw the remaining pesticides outside the house and in the fields. Residues analysis of 75 samples of 13 vegetables indicated that $58 \%$ of the vegetable samples contained no detectable level (NDL) of the monitored pesticides, $38 \%$ samples resulted in trace level of the pesticides residue or below the minimum residue level (MRL), while 4\% samples showed above MRL (EU Standard). Present study revealed ample scope for improvement on pesticide use and exposure, for which there is need of strong policy implementation, strengthening training, extension services and various awareness programs to farmers and agro-vets for judicious use of pesticides, health safety and environment protection.
\end{abstract}

Key-word:health, safety,knowledge, pesticide, residue

\section{INTRODUCTION}

Pesticides are widely used in agriculture to increase the yield, improve the quality, and extend the storage life of food crops (Fernndez-Alba and Garca-Reyes, 2008). In Nepal, there are 67 pesticides importers. Eight thousands five hundred fifty one resellers have received training on safe use of pesticides and storage management, of which 3493 license holders have been selling the pesticides through agro-vets. One thousands ninety eight types of pesticides by trade name, 108 common names have been registered for use under Pesticides Act 1991 and Rules 1993. According to the latest estimate, the annual imports of pesticides in Nepal is 345 tons (a.i.) with 33.25 percent insecticides, 48.35 percent fungicides, 15.49 percent herbicides, 2.37 percent Rodenticides, 0.034 percent biopesticides and 0.50 percent others, respectively. The gross sales and values account NRs. 374.90 million (\$4 million) per year (PRMS, 2014).

\footnotetext{
${ }^{1}$ Program Director, Plant Protection Directorate ,Email:sharmadilli@yahoo.com
} 
The presence of pesticides in food commodities has been always a matter of serious concern (Sharma et.al, 2012). In Nepal, Food Act 1967 and Food Regulation 1970 have established and implemented MRLs for pesticides in food products, but limited to cereals, pulses and their products, bottledwater and infant foods. Department of Food Technology and Quality Control (DFTQC) constantly monitor pesticide residues level in food products (Koirala and Tamrakar, 2008). The level of pesticide residues in food stuffs are generally legislated so as to minimize the exposure of the consumers to harmful or unnecessary intake of pesticides (Zorka and Serder, 2009). Nepal has already the system of quarantine for plants, animal and food. Different regulatory agencies under the Ministry of Agriculture Development are working at different custom points mandated to check pesticide safety of the food products. However, it has not been effective in practice so far at custom points due to technical lack of and inadequate laboratory facilities. Therefore, pesticide monitoring in food is necessary for domestic food products as well as entry and exit of food products.

Nepal is included under the category of LDC which has limited use of pesticide per capita and/or hectare. So, in comparison to other countries in the Asia Pacific Region, the use of chemical pesticides in Nepal is the lowest (142 gm a.i. /ha) (Thapa, 1997). Recently, Plant Protection Directorate (PPD) has revealed that $396 \mathrm{gm}$ a.i./ha chemical pesticides are being used in Nepal (PPD, 2015). Pesticide use, however, is much more intensive in areas that have greater access to markets( Sharma,2014). The use is higher in areas with intensive commercial farming of vegetables, fruits, tea, and cotton. Under the present scenario (Thapa, 1997; Palikhe, 2007), judicious and prudent use of pesticide by the Nepalese farmers is largely disregarded. The study also revealed that more than 85 percent of imported pesticides are applying only in vegetable crops in Nepal( Sharma et.al, 2015). All types of pesticides are not only repeatedly but also carelessly used. Farmers do not always know the active ingredient. Sometimes outdated pesticides are sold to farmers. Farmers use a mixture of chemicals together, and therefore, when incidents occur, it is difficult to specify which chemical is the main cause.

Most pesticides are broad spectrum in nature and kill target as well as non-target organisms. There are few safer pesticides, but their use has been extremely limited due to lack of publicity and farmers' knowledge. In fact, all pesticides endanger the health of both producers and consumers. However, majority of the farmers are unaware of pesticide types, level of poisoning, safety precautions and potential hazards on health and environment (Yassin et al., 2002). The resultant effects on human health include cancer, birth defects, reproductive problems, tumors and damage of liver, kidney and neural organs. To prevent such hazards, Nepal has also banned 15 pesticides includingPIC (Prior Informed Consent) listed pesticides (Methyl Parathion and Monocrotophos) in the country. Highly persistent types (POP pesticides), Phosphamidon and Organo-mercury fungicides, 
organochlorine including endosulfan and others some hazardous chemical pesticides have been banned in the country (PRMS, 2015). However, because of an open and porous border with India, there is a considerable, but unknown quantity of trade beween farmers close to the border. Hence, illicit/illegal import of pesticides issue needs to be addressed in multilateral approach with neighboring countries to prevent potential infiltration of banned/ unregistered pesticides (Palikhe, 2005).

Government of Nepal has developed policy for judicious use of pesticides and safety regulations, which has not yet been materialized at the farmer's level due to lack of studies on other alternatives of pest management, such as biological, botanicals, and safe chemicals including indigenous knowledge of farmer's practices, as basic component of Integrated Pest Management (Shrestha and Neupane, 2002). These are the basic components of IPM. The IPMFFS was initiated in Nepal in 1997 with the support of Food and Agriculture Organization (FAO) (PPD, 2010). It has been an important approach of pest control strategy which encourages applying measures that causes least disruption of agro-ecosystem. Therefore, establishment and functioning of bio-agent rearing laboratory, studies of locally available botanical pesticides and residue study laboratories can exploit locally available natural resources of pest management and substantially help farmers, researchers, and policy makers to implement related acts. Vegetable is a very important crop grown from high hill to terai in Nepal. There are 3243521 vegetables growers reported in Nepal, which is about 69.3 percent of the total household (CBS, 2010). More than 200 vegetables can be grown in Nepal but only 50 species are in commercial cultivation (SEAN, 1995). India is the second largest producers of vegetables after China which produces 87.53 million tons (Chadha, 2001) and accounts for 13.4 percent of world productions (Karanth, 2002.).

\section{PESTICIDE USE PATTERN}

Recently PPD, PRMS has studied the use pattern of pesticides in Nepal and found that $45 \%$ of respondents stated that the amount of pesticide use every year increased whereas $32 \%$ indicated that the amount of pesticide use every year decreased and $23 \%$ indicated that they didn't notice any change (Table 1). Increasing use of pesticides on vegetables is a growing environmental problem and food safety threat in Nepal where vegetable farming is becoming more intensive and a widespread (PPD, 2015)

Table1:Pesticide Knowledge and Perception of Farmers

\begin{tabular}{|l|l|l|l|}
\hline No & \multicolumn{1}{|c|}{ Pesticide use situation } & Frequency & Responses in percent \\
\hline & & & \\
\hline 1 & Use of pesticide decreased & 380 & 32 \\
\hline 2 & Use of pesticide increased & 532 & 45 \\
\hline 3 & Not so noticeable difference & 276 & 23 \\
\hline & Total & 1188 & 100 \\
\hline
\end{tabular}

Source: PPD (2015) 
On development region basis, the study also observed that the amount of pesticide used in FWDR is about 31.27 a.i.kg (5.43\%). The MWDR accounted for 45.66 a.i.kg (7.94\%) followed by WDR 66.35 a.i.kg (11.53\%), CDR 261.50 a.i.kg (45.48\%) and EDR 170.19 a.i.kg (29.62\%). The average per hectare consumption of pesticides in Far West, Mid-West, Western, Central and Eastern development region was 0.146 a.i.kg/ha, 0.225 a.i. $\mathrm{kg} / \mathrm{ha}, 0.276$ a.i. $\mathrm{kg} / \mathrm{ha}$, 1.015a.i.kg/ha, 0.616 a.i.kg/ha respectively. Details are provided in Table 2. On ecological basis, highest average pesticides use was in Terai $(0.995 \mathrm{a} . \mathrm{i} . \mathrm{kg} / \mathrm{ha})$ followed by Valley $(0.470$ a.i.kg/ha) Hill (0.314 a.i.kg/ha) and High hill (0.085 a.i.kg/ha) (Table 3) (PPD, 2015).

Table 2: Regional Scenario of pesticides use

\begin{tabular}{|l|l|l|l|}
\hline \multicolumn{1}{|c|}{ Regions } & \multicolumn{1}{|c|}{$\begin{array}{c}\text { Total pesticides } \\
\text { applied(kg) }\end{array}$} & \multicolumn{1}{|c|}{ Percentage } & Quantity(a.i.kg/ha) \\
\hline FWDR & 31.27 & 5.43 & 0.146 \\
\hline MWDR & 45.66 & 7.94 & 0.225 \\
\hline WDR & 66.35 & 11.53 & 0.276 \\
\hline CDR & 261.50 & 45.48 & 1.015 \\
\hline EDR & 170.19 & 29.62 & 0.616 \\
\hline Total & 574.97 & 100 & \\
\hline
\end{tabular}

Source: PPD (2015)

Table 3. Ecological Scenario of pesticides use

\begin{tabular}{|l|l|l|l|}
\hline \multicolumn{1}{|c|}{ Ecological Belt } & Total Pesticide applied (a.i. kg) & Percentage & \multicolumn{1}{|c|}{$\begin{array}{c}\text { Quantity (a.i. } \\
\text { kg/ha) }\end{array}$} \\
\hline High hill & 23.83 & 4 & 0.085 \\
\hline Hill & 114.4 & 20 & 0.314 \\
\hline Terai & 342.4 & 59 & 0.995 \\
\hline Valley & 94.22 & 17 & 0.470 \\
\hline Total & 574.9 & 100 & - \\
\hline \\
Source: PPD (2015)
\end{tabular}

\section{GOVERNMENT POLICIES AND PROGRAMS ON PESTICIDE}

There is a regulatory infrastructure established for the management of pesticides in Nepal. It covers all handling and use aspects of pesticides. The importers wishing to market and sell pesticides must submit an application dealing with the use of pesticides, toxicity and the correct use of pesticides in agriculture and health sector from the health point of view. No pesticide may be imported into the country without the appropriate certificate of importation issued by Registration Authority.

Large numbers of persistent chemical pesticides have been banned for agriculture and public health from 9th April, 2001 and also hazardous pesticides have been phased out from the use since 9th April, 2001. At present, prohibition on the use of Quinalphos, Ethion, Monocrotophos and Phorate in the tea field is being campaigned and implemented 
from 9th, May, 2005 because these pesticides are highly toxic. The pesticides to be imported, distributed, traded and used should be friendlier and less hazardous to health and environment More emphasis has been given to use organic pesticides as an alternative of chemical pesticides to control crop pests. Development and use of some microbial and botanical pesticides which are eco-friendly has opened a new field of bio-pesticides. The best know form of bio-pesticide is the Bacillus thuringensis (Bt). Eco-friendly neem formulations are also being used currently. IPM has been widely accepted as the alternative to pesticide application. The significant being phasing out of an environmental unfriendly pesticides are rigorous approval of the newer and more safer and specific molecules. Government has already conducted or is regularly lunching training programs to educate the concerned personnel. In Nepal, as in most of the other developing countries in the region, the capabilities, expertise and resources to fully implement the regulation are limited. Further, there is a need to strengthen the scientific and technical base for health and environmental risk assessment.

Government has initiated to analysis residue of vegetable in the vegetable whole sale market by applying rapid bioassay residue analysis technology. Rapid Pesticide Residue Analysis Laboratory established in the Kalimati vegetable and fruit whole sale market and it gave very good result for monitoring the use of pesticides in the vegetables and fruits. Due to the grand success of Rapid Pesticide Residue Analysis Laboratory, Government is establishing 6 more Rapid Pesticide Residue Analysis Laboratories in the different cities of Nepal very soon.

\section{OBJECTIVE}

The objective of the study was to document pesticides use patterns and its residue on vegetable crops.

\section{METHODOLOGY}

The study was conducted in selected vegetable pockets of three districts representing vegetable production areas in the mid hills and terai of central development region of Nepal. The three districts, namely: Bara, Dhading and Kavre are the main producers of vegetables to feed the huge population of Kathmandu valley and with massive amount of pesticides application as well.

The survey was conducted in vegetable crop seasons. For this, semi-structured questionnaire was prepared and initially tested on a group of farmers in Kathmandu district. The questionnaire was finalized incorporating their comments and suggestions. Then, two hundred vegetable growing farmers were selected as mentioned in the sampling frame and interviewed using semi- structured questionnaires in six vegetable pockets of three districts, i.e. Bara, Dhading and Kavre. 
Seventy five fresh samples were collected and analyzed at accredited laboratory for determining the residual level (MRL) on major common vegetables grown in study pockets. The samples of different fresh vegetables collected from study areas in each district.

\section{RESULT AND DISCUSSION}

\section{FARMER'S KNOW HOW ABOUT PESTICIDE APPLICATION}

Majority of the farmers had lack of knowledge about the proper use of pesticides. Farmers mostly applied pesticides without knowing the population of insect pests, natural enemies and crop condition. It was clear from the survey that 72 percent of the farmers paid attention on acquiring information about the effectiveness of pesticide to control the target pests. While 65 percent of the farmers noticed the expiry date of pesticides, and only a few farmers considered the adverse effects of pesticide on human health and environment (Table 4). This study showed that overwhelming majorities of the farmers were not concerned about the adverse effects of pesticides on human health and environmentpollution. Hence, the practices of buying pesticides focusing on effectiveness to target pests and ignoring adverse effects of pesticides on human health and environment, which harm to everyone is a serious concern.

Table 4. Farmer's practices while buying the pesticides in vegetable growing areas

\begin{tabular}{|c|c|c|c|c|c|c|c|c|c|c|c|}
\hline \multirow{3}{*}{$\begin{array}{l}\text { Ecological } \\
\text { zone }\end{array}$} & \multirow{3}{*}{ District } & \multicolumn{10}{|c|}{ Farmers mainly concerning on pesticide effects } \\
\hline & & \multicolumn{2}{|c|}{$\begin{array}{c}\text { Label } \\
\text { contain }\end{array}$} & \multicolumn{2}{|c|}{$\begin{array}{l}\text { Effectiveness } \\
\text { of pesticide } \\
\text { to control } \\
\text { the target } \\
\text { pests }\end{array}$} & \multicolumn{2}{|c|}{$\begin{array}{c}\text { Adverse } \\
\text { effect of } \\
\text { pesticide } \\
\text { on human } \\
\text { health }\end{array}$} & \multicolumn{2}{|c|}{$\begin{array}{c}\text { Adverse } \\
\text { effects of } \\
\text { pesticide on } \\
\text { environment }\end{array}$} & \multicolumn{2}{|c|}{$\begin{array}{c}\text { Expiry } \\
\text { date of } \\
\text { pesticide }\end{array}$} \\
\hline & & Fre & $(\%$ & Freq & $(\%)$ & Freq & $(\%)$ & Freq & $(\%)$ & Fre & $(\%)$ \\
\hline & & q & ) & & & & & & & $q$ & \\
\hline Terai & Bara & 43 & 43 & 92 & 92 & 18 & 18 & 17 & 17 & 84 & 84 \\
\hline \multirow[t]{2}{*}{ Mid hills } & Dhading & 17 & 34 & 23 & 46 & 1 & 2 & 0 & 0 & 34 & 68 \\
\hline & Kavre & 10 & 20 & 29 & 58 & 1 & 2 & 1 & 2 & 12 & 24 \\
\hline Mid hills total & & 27 & 27 & 52 & 52 & 2 & 2 & 1 & 1 & 46 & 46 \\
\hline Grand Total & & 70 & 35 & 144 & 72 & 20 & 10 & 18 & 9 & 130 & 65 \\
\hline
\end{tabular}

\section{HANDLING OF LEFT OVER PESTICIDES}

Farmers purchased pesticides from Agro-vets and applied to their crops for managing pests. They did not get the actual required amount of pesticides; so they bought whatever available amount from the shop and used in their crops. The result showed that majority of them $(51.5 \%)$ kept the remaining pesticides in their house freely, whereas 23.5 percent farmers destroyed the remaining pesticides; either buried or burnt. It was also found that 22.5 percent of farmers did not care and threw the remaining pesticides outside the house and in the fields (Table 5). Hence, it was clear that the handling of remaining pesticide was 
improper and unsound practice, which further created adverse effects to human health and polluted environment.

Table 5. Handling of leftover pesticides by farmers in vegetable growing areas, 2012

\begin{tabular}{|c|c|c|c|c|c|c|c|c|c|}
\hline \multirow{2}{*}{ Eco-zone } & \multirow{2}{*}{ District } & \multicolumn{2}{|c|}{$\begin{array}{c}\text { Keep in house/ } \\
\text { store freely }\end{array}$} & \multicolumn{2}{|c|}{ Bury/burn } & \multicolumn{2}{|c|}{$\begin{array}{c}\text { Throw outside } \\
\text { their house }\end{array}$} & \multicolumn{2}{|c|}{$\begin{array}{l}\text { Give to their } \\
\text { friends }\end{array}$} \\
\hline & & Freq & Percent & Freq & $\begin{array}{c}\text { Perce } \\
\text { nt }\end{array}$ & Freq & $\begin{array}{c}\text { Percen } \\
t\end{array}$ & Freq & Percent \\
\hline Terai & Bara & 59 & 59 & 29 & 29 & 11 & 11 & 1 & 1 \\
\hline \multirow{2}{*}{ Mid hills } & Dhading & 9 & 18 & 6 & 12 & 32 & 64 & 3 & 6 \\
\hline & Kavre & 35 & 70 & 12 & 24 & 2 & 4 & 1 & 2 \\
\hline Mid hills total & & 44 & 44 & 18 & 18 & 34 & 34 & 4 & 4 \\
\hline Grand Total & & 103 & 51.5 & 47 & 23.5 & 45 & 22.5 & 5 & 2.5 \\
\hline
\end{tabular}

\section{PESTICIDE RESIDUE ANALYSIS}

Residues of twelve pesticides were analyzed using Gas Chromatography MS method in 75 samples of different 13 vegetables (carrot, cucumber, brinjal, okra, cowpeas, green beans, tomatoes, chilli, cauliflower, bitter guard, bottle guard, potato and pumpkin) selected for this study are common vegetables in Nepal (Figure1).

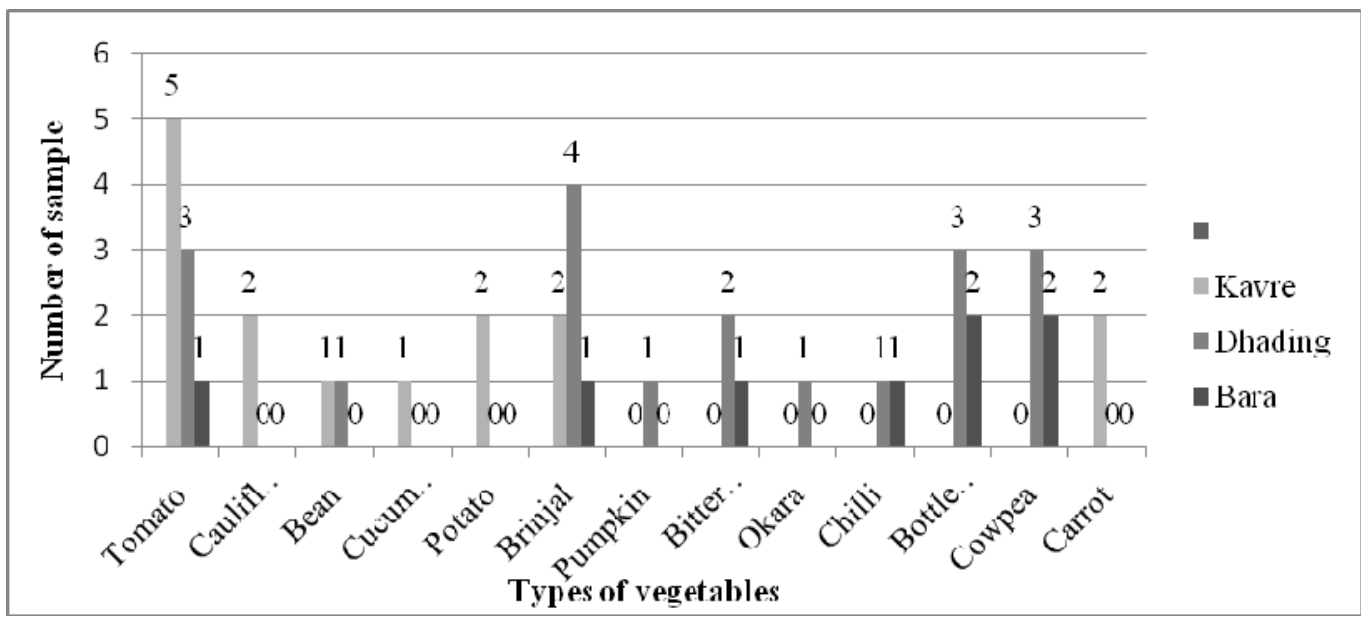

Figure 1. Fresh vegetable samples analyzed for pesticide residues from Kavre, Dhading and Bara

\section{STUDY AREAS}

Most of the vegetable samples analyzed did not contain pesticide residues above the accepted maximum residue limit (MRL) as adopted by EU standard, although some pesticide residues have been detected in certain levels. The result obtained showed that 58 percent of the vegetable samples analyzed contained no detectable level (NDL) of the monitored pesticides, 38 percent of the samples resulted in trace level of the pesticide residue or level below the MRL, while four percent of the samples showed above MRL (Figure 2). 


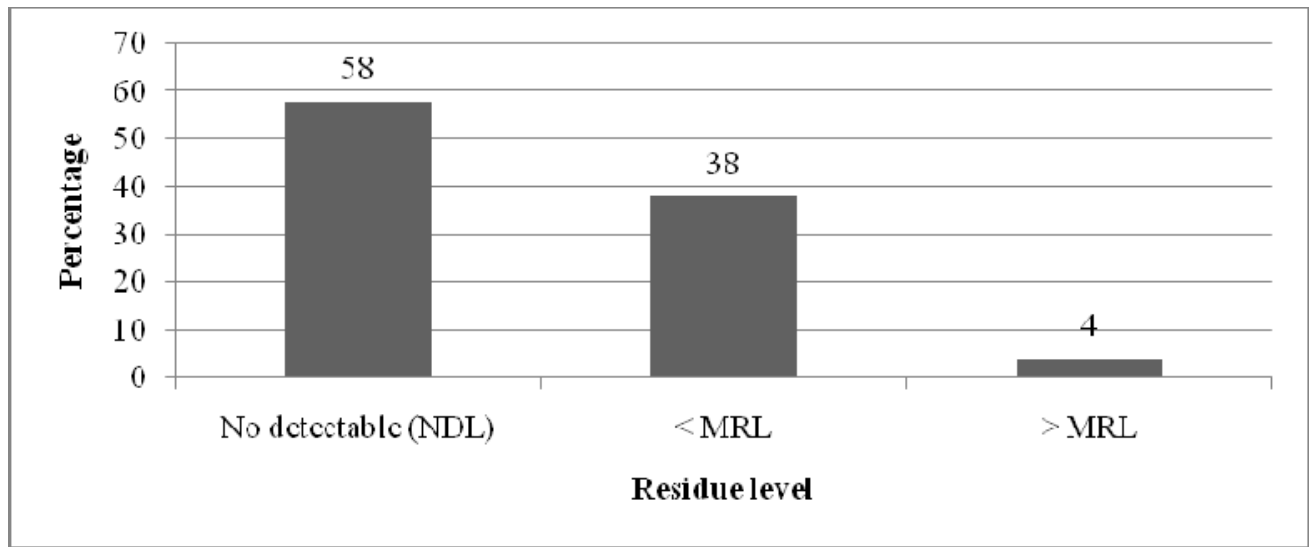

Figure 1. Vegetable sample analysis and residue detected under different categories

The analysis detected the highest concentration of Cypermethrin in tomato and brinjal. Likewise, concentration of Deltamethrin was the highest in cowpea followed by cauliflower, tomato and brinjal. The concentration of Carbandazim and Mancozeb were also the highest in tomato followed by bottle guard and chilli.

\section{CONCLUSION AND RECOMMENDATION}

Pesticide Act 2048 has not mentioned residue part of pesticides and it is urgent to revise and incorporate in the Act. A sound system of monitoring for pesticide residues at the local level and residue analysis at market place can control fruit and vegetables growers, who are competing with chemical imports. This will encourage consumers to trust local produce. Establishment of regional centre is necessary for the prevention and management of pesticide poisoning, enhanced surveillance, training, and community action. Dissemination of information about insights, experience and lessons learnt from research and interventions is necessary as recommendations to interlink global policy and local action for prevention and management of pesticide hazards. Therefore, information, education and communication sectors need strengthening to raise awareness about proper use of pesticides and its safety measures.

Residues analysis of 12 insecticides from 75 samples of 13 vegetables indicated that over half of the vegetable samples contained no detectable level (NDL) of the monitored pesticides, $38 \%$ samples resulted in trace level of the pesticides residue or below the minimum residue level (MRL), while 4\% samples showed above MRL (EU Standard). Pesticide Act 2048 has not mentioned residue part of pesticides and a sound system of monitoring for pesticide residues at the local level and residue analysis at market place is lacking. 


\section{RECOMMENDATION}

- $\quad$ Selection of appropriate pesticides and their handling and use as per the label are the most important steps for safe use of chemical pesticides. For this, the Government needs to develop mechanisms for enforcing the acts and regulations for the overall management and use of pesticides, adopting FAO guidelines with adequate educational and training interventions.

- $\quad$ Long-term implications of pesticide use on human health and environment need to be studied for eco-friendly sustainable agriculture, safety to human health and the environment as a whole.

- The quality of pesticides and their residue on marketable products is required to monitor regularly for public safety. Therefore, establishment of the Rapid Pesticide Residue Analysis Laboratory and systematized residue monitoring plan should be enforced in the country.

\section{REFERENCES}

CBS. 2010. Nepal vegetable crops survey 2009-10. A Statistical Report. National Planning Commission Secretariat, Central Bureau of Statistics, Kathmandu, Nepal.

Chadha, K. L. (ed.)., 2001. Handbook of horticulture. Indian Council of Agricultural Research, New Delhi, India.

Fernndez-Alba, A. R. and J. F. Garca-Reyes., 2008. Large-scale multi-residue methods for pesticides and their degradation products in food by advanced LC-MS. Trac-Trend. Anal. Chem. 27 (11): 973-990.

Karanth, N. G. K., 2002. Challenges of Limiting Pesticide Residues in Fresh Vegetables: The Indian Experience. In E. Hanak, E. Boutrif, P. Fabre and M. Pineiro, (Scientific Editors), Food Safety Management in Developing Countries. Proceedings of the International Workshop, CIRAD-FAO, Montpellier, France. 11-13.

Koirala, P. and A.S. Tamrakar., 2008. Analytical capability on pesticide analysis in food in Nepal. Proceeding of $5^{\text {th }}$ National Seminar organized by Nepal Academy of Science and Technology, Kathmandu, Nepal. pp10-12.

Palikhe, B. R., 2005. Pesticide Management in Nepal: In view of code of conduct. Paper presented at the regional workshop on international code of conduct on the distribution and use of pesticides: Implementation, monitoring and observance, Bangkok, Thailand.

Palikhe, B. R., 2007. Problem of misuse of pesticides and management in Nepal. Paper presented at the workshop on chemical management in Nepal: Strategy development and awareness generation, 29 August, 2007, Kathmandu. Nepal.

PPD., 2010. Annual progress report. Plant Protection Directorate, Hariharbhawan, Lalitpur, Nepal. PPD., 2015. Annual progress report. Plant Protection Directorate, Hariharbhawan, Lalitpur, Nepal.

PRMS., 2014. Pesticide statistic book. Pesticide Registration and Management Section, Plant Protection Directorate, Hariharbhawan, Lalitpur, Nepal.

PRMS., 2015. List of registered pesticides. Pesticide Registration and Management Section, Plant Protection Directorate, Hariharbhawan, Lalitpur, Nepal.

SEAN., 1995. Vegetable seed survey. Kathmandu, Nepal. 
Sharma., D.R.2014.Practical Aspects of Pesticide Risk Assessment and Phasing out of Highly Hazardous Pesticides (HHPs) in Nepal. Paper Present at Regional Workshop in Nanjing, China, 19-22 May , 2014

Sharma., D. R, R. B. Thapa, H. K. Manandhar , S. M. Shrestha and S. B. Pradhan. 2012. Use of Pesticides in Nepal and Impacts on Human Health and Environment. The Journal of Agriculture and Environment Vol: 13, 67-74.

Sharma, Dilli Ram, Thapa Resham Bahadur, Manandhar Hira Kaji, Shrestha Sundar Man, Pradhan Shree Baba. 2014. A case study on attitude of Vegetable growing farmers towards pesticides use in Nepal. Annals of Plant Protection Sciences Year : 2014, Volume : 22, Issue : $2: 414-417$

Shrestha, P. L. and F. P. Neupane., 2002. Socio-economic contexts on pesticide use in Nepal. J. Landschaft. Umwelt, Braunschweig, Germany. pp205-223.

Thapa, R. B., 1997. An overview of pesticides pollution in Nepal. Nepalese Horticulture, J. Nepalese Horti Soci. 1:30-39.

Yassin, M. M., T.A. Abu Mourad and J.M. Safi., 2002. Knowledge, attitude, practice, and toxicity symptoms associated with pesticide use among farm workers in $t$ he Gaza Strip. J. Occup. Environ. Med. (59): 387-394.

Zorka, K. and M. Serder., 2009. Screening of fresh fruit and vegetables for pesticide residues on Croatian market. J. Food. Control. 20(4): 419-422. 